\title{
Por uma Abordagem Relacional do Desenvolvimento Territorial Rural ${ }^{1}$
}

\author{
Alair Ferreira de Freitas ${ }^{2}$
}

Resumo: A institucionalização dos programas de desenvolvimento territorial rural foi acompanhada de uma intensa efervescência acadêmica sobre o tema. Contudo, uma das críticas mais difundidas a respeito da literatura produzida é que ela possui um caráter normativo, falta-lhe substância teórica sobre interação social e, assim, o território parece estar sendo reificado pelas políticas públicas. Este ensaio possui como objetivo construir um quadro analítico para compreender os processos sociopolíticos subjacentes à implementação das políticas de desenvolvimento territorial rural, organizando um instrumental conceitual que estruture uma abordagem relacional do desenvolvimento territorial. Considera-se que a abordagem aqui empreendida poderá dotar as análises empíricas de sentidos diferentes daqueles que já se expressavam em trabalhos anteriores sobre o mesmo objeto, alcançando dimensões ainda pouco exploradas nos estudos do desenvolvimento territorial, como a rede de organizações, sua historicidade, suas configurações e os elementos sociais e institucionais que condicionam as intervenções dos atores no território, orientando sua trajetória de desenvolvimento. Essa construção teórico-analítica leva à premissa de que "atores", "redes" e "instituições" sintetizam os principais elementos constitutivos da dinâmica social dos territórios e, assim, elementos definidores da trajetória do desenvolvimento territorial rural.

Palavras-chaves: Desenvolvimento territorial; Redes sociais; Território.

Abstract: The institutionalization of rural territorial development programs was
accompanied by an intense academic effervescence on the subject. However, one of the most
widespread criticisms of the literature produced is that it has a normative character, it lacks
theoretical substance on social interaction and thus the territory seems to be reified by
public policies. This essay has aimed to build an analytical framework for understanding
the socio-political processes underlying the implementation of rural territorial development
policies, organizing a conceptual instrument that would structure a relational approach to
territorial development. It is considered that the approach adopted in this paper can provide
empirical analyzes of different directions for those already expressed in previous works on

1. Data de submissão: 14 de novembro de 2015. Data de aceite: 19 de julho de 2016.

2. Universidade Federal de Viçosa. Viçosa, Minas Gerais. E-mail: alair.freitas@ufv.br 
the same object, reaching yet unexplored dimensions in the territorial development studies, such as the network of organizations, its historicity, its settings and the social and institutional factors that influence the activities of the actors in the territory, guiding its development trajectory. This theoretical and analytical construction leads to the assumption that "actors", "networks" and "institutions" summarize the major components of the social dynamics of the territories and, therefore, defining elements of the trajectory of rural territorial development.

Key-words: Territorial development; Social networks; Territory.

DOI - http://dx.doi.org/10.1590/1234-56781806-94790540405

Classificação JEL: Z13, Z18.

\section{Introdução}

A definição de territórios como recorte espacial de intervenção governamental sobre o desenvolvimento rural ganhou atenção com a criação do Programa Nacional de Desenvolvimento Sustentável dos Territórios Rurais (Pronat), em 2003, e, posteriormente, o Programa Territórios da Cidadania (PTC), em 2007. Estes programas surgiram no âmbito do governo federal do Brasil, principalmente por meio da Secretaria de Desenvolvimento Territorial (SDT) do Ministério do Desenvolvimento Agrário (MDA), representando uma inovação conceitual e discursiva, especialmente para os agentes governamentais. Mudar o planejamento das políticas de desenvolvimento rural da escala municipal para a territorial foi consequência, dentre outros fatores, da constatação de que os projetos locais eram restritos demais para provocar mudanças significativas nas instituições que reproduziam as desigualdades em nível supralocal. Tal mudança também implicou a necessidade de se considerar o rural para além de um viés setorial, como sinônimo de agrícola, passando a valorizar, por exemplo, as potencialidades naturais e os modos de vida dos agricultores. Estes elementos conferiram à política um escopo voltado para a redução da pobreza rural, priorizando um público específico, aquele regulamentado pela categoria normativa de "agricultor familiar", que envolve pequenos produtores rurais, agricultores sem-terra, assentados de reforma agrária, ribeirinhos, quilombolas etc.

A institucionalização dos programas de desenvolvimento territorial rural foi acompanhada de uma intensa efervescência acadêmica sobre o tema, tanto no Brasil como em outros países da América Latina, fomentada principalmente pelo apoio (institucional e financeiro) de organizações multilaterais de promoção do desenvolvimento a partir de meados dos anos 1990. Contudo, uma das críticas mais difundidas a respeito da literatura produzida sobre o tema é que, em sua maioria, ela possui um caráter normativo, contribuindo pouco para explicar as raízes dos processos que conduzem o desenvolvimento nos territórios rurais criados pelas políticas governamentais (FAVARETO, 2007; FAVARETO et al., 2015). Ademais, o território parece estar sendo reificado pelas políticas públicas e na maioria das pesquisas, tornando-se uma entidade, às vezes coesa e homogênea, personificada na estrutura de um Colegiado Territorial.

Um modo de superar tal acepção reificada seria partir de bases explicativas que relativizem a noção de território como um espaço material ou físico ou uma estrutura formal colegiada, que, apesar de se constituir como o arranjo organizacional que inicialmente operacionaliza uma 
política pública, não encerra em si o processo de desenvolvimento, tampouco se comporta exatamente como prescrito pelo Estado. Os processos decorrentes da implementação da política (ou subjacentes a ela) podem ser tão centrais quanto seus resultados, pois é naqueles que se percebe a dinâmica de interação dos atores, seus posicionamentos e discursos, sua ascensão ou exclusão em um determinado contexto.

Para além de explicar o desenvolvimento territorial a partir da implementação de políticas públicas e do financiamento dos territórios rurais, como a maioria dos estudos especializados já o fez, este ensaio considera que o funcionamento dos territórios está atrelado a processos sociopolíticos que extrapolam a estrutura formal instituída e legitimada pelo Estado. A perspectiva proposta exigiu focalizar analiticamente as relações sociais das quais emerge o arranjo organizacional do território e sua contingência histórica.

Abramovay (2000) aponta que não se trata de distinguir as potencialidades e limitações geográficas de um território ou olhar estritamente para as organizações formalizadas para compreender seu desenvolvimento. Para o autor, é preciso estudar, sobretudo, a construção das redes e das instituições que possibilitam ações cooperativas capazes de enriquecer o tecido social e potencializar as organizações que nele interagem. Assim, a configuração das relações que compõem este tecido social seria fator determinante do desenvolvimento territorial. Essa dinâmica social subjacente aos processos de desenvolvimento dos territórios rurais é ainda pouco explorada nos estudos acadêmicos, mas se revela uma chave explicativa sobre as diferenças entre territórios, o desempenho de políticas públicas e o futuro de regiões rurais.

A partir destas reflexões, este ensaio possui como objetivo construir fundamentos teóricos e analíticos para compreender os processos sociopolíticos subjacentes à implementação das políticas de desenvolvimento territorial rural, considerando tais processos como essenciais para compreender a dinâmica do desenvolvimento rural nos territórios. Em outros termos, empre- ende-se aqui um esforço cognitivo de organizar um instrumental conceitual para interpretar as dinâmicas sociais dos territórios rurais, emergindo daí uma abordagem relacional do desenvolvimento territorial, ainda pouco trabalhado nas pesquisas sobre o tema.

A seguir, apresenta-se a organização do referencial que embasa a abordagem relacional proposta. Inicialmente explicita-se a discussão complementar acerca das dinâmicas sociais do desenvolvimento territorial rural, dando ênfase à importância das relações sociais para a compreensão do fenômeno. Em seguida articulam-se os referenciais da sociologia econômica e do neoinstitucionalismo, bases teóricas escolhidas como fundamento do ensaio. A partir disso, se estrutura o quadro analítico, como síntese teórica da abordagem relacional. Por fim, são feitas algumas considerações a título de conclusão do ensaio.

\section{Fundamentos para a proposição de uma abordagem relacional do desenvolvimento territorial}

Para iniciar essa discussão, antecedendo a proposição de um quadro analítico, o ponto de partida é relativizar a noção de território, superando sua concepção como espaço físico e limite geográfico de transações econômicas. Território, sob uma perspectiva relacional, é visto aqui a partir das relações sócio-históricas que o constituem, mediadas pelas representações que dele são feitas e que balizam as intervenções sobre ele. Reforçar a dimensão do território enquanto representação é ressaltar seu valor simbólico (HAESBAERT, 2006). A esta dimensão está associada à noção de territorialidade, comumente relacionada com a representação de um símbolo do território, como um valor.

A territorialidade, de acordo com Raffestin (1993), é sempre definida como um conjunto de relações situadas num sistema tridimensional que articula sociedade-espaço-tempo. Ela é dinâmica, pois os elementos que a constituem variam no tempo. Compreender o desenvolvimento de 
um território requer, assim, apreender as relações sociais em seu contexto sócio-histórico e espaço-temporal, pois contextualiza a sua territorialidade.

Para Haesbaert (2007), territorialidade não é apenas uma abstração analítica ou epistemológica do território como espaço,

“[...] é também uma dimensão imaterial, no sentido ontológico de que, enquanto 'imagem' ou símbolo de um território, existe e pode inserir-se eficazmente como uma estratégia político-cultural, mesmo que o território ao qual se refira não esteja concretamente manifestado" (p. 25).

A perspectiva acima enunciada alude à questão de que o desenvolvimento territorial extrapola prescrições de políticas governamentais, apesar de elas poderem induzir a cooperação e fomentar a organização produtiva em um território. Essa abordagem busca ressonância no trabalho de Zaoual (2006), que ressalta a importância da pluralidade de caminhos para que os atores de um território possam conduzir seus próprios destinos de acordo com a sua diversidade cultural e suas "verdades locais". Para o autor, considerar as especificidades locais contribui para perceber a impossibilidade de transpor modelos de economia, administração e desenvolvimento de um território para outro, o que ele denominou de "desenvolvimento transposto".

Pecqueur (2005) também relativiza a construção conceitual do desenvolvimento territorial e afirma que

"[...] o desenvolvimento territorial não pode ser implantado por decreto; permanece uma construção dos atores, mesmo que políticas públicas apropriadas possam estimular e mobilizar esses atores" (p. 12).

Conforme sublinha o autor, essa construção só pode ser concebida como dinâmica e, portanto, inserida no tempo. Abramovay (2006) complementa, argumentando que territórios se constituem por laços informais, estabelecidos por interações não mercantis e nem sempre institu- cionalizadas, que moldam a própria identidade dos indivíduos e dos grupos sociais.

Como baldrame para um enfoque relacional do desenvolvimento [territorial] rural, Schmitt (2011) argumenta que,

“[o]s atores sociais, suas características e dinâ-
micas de interação, só existem, efetivamente,
como parte de uma teia de interdependên-
cias, impossível de ser apartada de seus con-
textos temporais e espaciais de existência.
Colocam-se, com isso, em questão, conceitos
e pares de oposições fortemente imbricados
na produção do discurso e nos métodos de
investigação das ciências sociais, entre eles:
estrutura/ação, macro/micro, sociedade/indi-
víduo. [...] O que éimportante destacar é que a
incorporação desse tipo de enfoque ao estudo
das políticas e práticas de desenvolvimento
implica uma ruptura com perspectivas de
análise e modos de explicação dos processos
de mudança social centrados em unidades,
sujeitos sociais ou circunscrições territoriais
pré-estabelecidos - 'o Estado', 'as populações
pobres', 'as comunidades' -, colocando em
tela os processos e campos de relações nos
quais se constituem os objetivos, os quadros
de referência e os próprios agentes do desen-
volvimento" (p. $86-88$ ).

Em recente trabalho, Berdegué, Bebbington e Escobal (2015) sintetizaram proposições teóricas que corroboram com a abordagem relacional que aqui se propõe. Para eles, há fatores socialmente construídos que têm efeitos significativos e territorialmente específicos sobre os resultados do desenvolvimento. Os autores afirmam, a partir dos resultados de seu programa de pesquisa, que mudanças institucionais nos territórios são efetuadas por formas individuais e coletivas da agência humana, e não por plataformas de intervenção de agências externas. Torna-se relevante, assim, analisar as dinâmicas sociais nas quais formas de organizar o território são construídas, representações sobre ele são elaboradas e as interações entre os atores se desenvolvem e institucionalizam.

Abramovay (2006) foi uma das principais inspirações para se construir uma abordagem com 
tal enfoque, pois sinaliza certas fragilidades teóricas da literatura contemporânea sobre desenvolvimento territorial e indica caminhos a partir de uma perspectiva interacionista com base numa sociologia econômica aplicada ao desenvolvimento territorial. O referido trabalho sublinha dois dos problemas de que padece a literatura contemporânea sobre desenvolvimento territorial. O primeiro deles é o já mencionado caráter normativo de que, com frequência, se revestem os trabalhos científicos. O segundo é a falta de uma teoria da interação social para fundamentar teoricamente a noção de desenvolvimento territorial. A partir da análise de experiências internacionais de desenvolvimento sistematizadas por estudiosos da área, o autor assevera sobre a inexistência de elementos teóricos que expliquem concretamente as virtudes capazes de conduzir ao processo localizado de desenvolvimento. $\mathrm{O}$ foco analítico sobre a interação social é, de certa forma, substituído por elementos histórico-culturais associados a situações ditas virtuosas, como a partir da perspectiva culturalista de Putnan (1996) sobre o capital social no desenvolvimento da terceira Itália.

Estes tipos de estudos incorrem no risco de substituir a análise das interações sociais e de seus conflitos pela análise da presença ou ausência de coesão nos territórios, sem que se observe sua natureza. Concorda-se com Abramovay (2006), que a literatura sobre territórios e desenvolvimento territorial tem sido muito mais voltada à policy do que à politics, destacando elementos culturais e de identidade muitas vezes vinculados ao acesso a uma política pública, em detrimento da análise da forma como as relações sociais estão estruturadas, dos conflitos políticos e dos interesses contraditórios que lhe constituem.

Como assinalado por Boiser (1999), os estudos do desenvolvimento precisam superar suas raízes cartesianas e se enveredarem definitivamente para a dimensão holística e sistêmica do desenvolvimento, abordando-o com maior ênfase na sinergia do que na entropia. Associado a esta crítica, pode-se retomar aquela feita por Navarro (2001) e Pecqueur (2005) acerca do caráter excessi- vamente determinista e estruturalista de grande parte das análises encontradas sobre o assunto. Respaldado em tais críticas, e no percurso analítico já delineado anteriormente, admite-se neste ensaio que é inegável a necessidade de se revelar a natureza não material do desenvolvimento territorial, concebido também e, principalmente, como fenômeno axiológico, social e espacialmente situado. Há, por esta via, uma clara demanda de novos referenciais epistemológicos e teóricos para se compreender as dinâmicas territoriais de desenvolvimento.

Se se admite que os territórios possam ser estudados a partir da interação social entre seus atores, então seria fundamental compreender teoricamente a natureza destas interações, revelando os processos de cooperação e conflito em torno dos quais se constroem os territórios (ABRAMOVAY, 2006). Compreender dinâmicas sociais dos territórios rurais, portanto, pode contribuir para identificar alguns dos fatores que explicam suas diferentes formas de organização e os rumos pelos quais o processo de desenvolvimento é conduzido.

De acordo com Favareto e Schröder (2007), é preciso conceber o território como um campo, no sentido sugerido por autores como Bourdieu (1989) e Fligstein (2003), como um todo estruturado num sistema de posições e oposições, cuja estrutura é dada pela distribuição das diferentes formas de capital, e no qual os indivíduos estão em constante luta pelas melhores colocações nesta estrutura. O resultado dessa dinâmica não é necessariamente a convergência e a cooperação entre seus agentes, mas, antes, o conflito e a disputa que constantemente reconfiguram a rede de relações.

Esse argumento dá relevo a uma consideração sobre as regras (formais e informais) construídas pelos atores de um território e que orientam suas interações, buscando a minimização dos conflitos e a estabilidade do sistema social. Os atores interagem entre si no território e podem estabelecer parcerias a partir dessa interação, constituindo laços de confiança e cooperação, o que lhes permitiria estabelecer normas e convenções que 
são aceitas, legitimadas e seguidas pela maioria geral ou por grupos específicos, formando coalizões políticas (SCHNEIDER, 2009). As regulamentações das políticas públicas, que implicam o estabelecimento de diretrizes institucionais para seu acesso, também constituem certa normatização para as interações no território, inclusive determinando o foco dos projetos territoriais e a maneira como eles devem ser implementados. Essa dimensão institucional do desenvolvimento territorial é um foco que merece constante atenção, por revelar dispositivos que influenciam a ação dos atores e que é por elas influenciada.

A ação dos atores e as relações entre eles seriam determinantes das dinâmicas de desenvolvimento rural, mas não devem ser compreendidas desconectadas dos dispositivos institucionais que lhe possibilitam certa regularidade e as legitimam, que tipificam as ações e os atores e que moldam a ação coletiva. A socialização dos atores no âmbito dos territórios rurais pressupõe processos de institucionalização e desinstitucionalização mediados pelas relações sociais e instituições que lhes servem de referência. De acordo com Favareto (2010b), compreender as dinâmicas territoriais do desenvolvimento rural implica lidar com os aspectos não diretamente mercantis que influenciam as regras de apropriação e regulação do uso social dos territórios e da cooperação e conflito entre os atores locais.

Considerando estas discussões, torna-se mister insistir numa aproximação entre categorias que envolvem a análise das relações sociais e outras que as contextualizem institucionalmente. Para tanto, definiu-se dois eixos distintos de modelo teórico explicativo: o neoinstitucionalismo e a nova sociologia econômica, apresentados a seguir. A convergência entre essas perspectivas teóricas ${ }^{3}$ reside na necessidade de contextualizar as ações sociais e considerar os elementos que condicionam as intervenções dos atores no território.

3. Entende-se que as convergências entre estas correntes teóricas são reais (como mostra MIZRUCHI, 2006), embora não se ignore o fato de que os embates teóricos e acadêmicos existam.

\section{Contribuições da sociologia econômica para o estudo do desenvolvimento territorial}

Para substanciar uma abordagem relacional do desenvolvimento territorial rural buscou-se uma aproximação com a chamada Nova Sociologia Econômica (NSE) ${ }^{4}$, que tem ganhado grande expressão nas ciências sociais por dar explicações sociológicas a fenômenos econômicos, principalmente sobre uma perspectiva microanalítica, dando destaque aos atores e, sobretudo, às relações sociais. Está no cerne da NSE analisar a origem sócio-histórica dos fenômenos econômicos ao focalizar o papel das relações sociais nas ações individuais, na formação de coalizões e no condicionamento de processos de desenvolvimento. Uma das principais premissas da NSE é que "[...] todos os fenômenos econômicos são sociais por sua natureza; estão enraizados no conjunto ou em parte da estrutura social" (SWEDBERG, 2004, p. 8).

Seguindo a trilha desta abordagem, as relações sociais cessam de ser relegadas a um papel residual para adquirir expressão enquanto categoria central de análise dos processos de desenvolvimento. $\mathrm{O}$ enfoque relacional é eminente, pois a formação das preferências individuais e coletivas é pensada a partir e como produto das interações sociais. Isso significa que para além de interesses econômicos, os atores almejam também objetivos sociais e políticos, como reconhecimento e poder. Estes argumentos integram as proposições centrais da NSE, que, para Swedeberg e Granovetter (1992), podem ser sintetizadas em três principais pontos:

4. Adota-se aqui o termo "Nova Sociologia Econômica" que, segundo Swedberg (2004), foi cunhado por Mark Granovetter em uma conferência pronunciada na Associação Norte-Americana de Sociologia, em Washington, em 1985. O autor contrastava aí a moderna sociologia econômica com a "velha sociologia econômica" dos anos de 1960 (Parsons, Moore etc.). Na literatura brasileira, Abramovay (2006) advoga o uso da NSE como ferramenta analítica para se compreender os processos de desenvolvimento territorial. 
1. Ação econômica é uma forma de ação social;

2. Ação econômica é socialmente situada; e

3. Instituições econômicas são construções sociais.

Granovetter (2003), um dos principais expoentes da NSE, considera fundamental acrescentar as motivações não econômicas como pressuposto do comportamento econômico. Fukuyama (2006) também advoga sobre isso; para ele, a lei, os contratos e os interesses econômicos fornecem uma base necessária, mas insuficiente para garantir a estabilidade e o desenvolvimento das sociedades pós-industriais. A confiança, a reciprocidade e as obrigações morais são também elementos basilares para isso. Não se trata, pois, de um anacronismo numa sociedade moderna, mas de condições fundamentais para o desenvolvimento.

Não se pode esquecer, porém, como afirma Raud-Mattedi (2005), do papel das normas jurídicas e morais que regem as relações em um determinado espaço, pois a confiança nem sempre decorre de relações pessoais. Se muitas relações econômicas são mediatizadas por relações pessoais, outras não necessariamente passam por elas e nem por isso resultam obrigatoriamente em oportunismo. Uma das críticas mais recorrentes das análises de redes de relações sociais passa por aí, especificamente na ausência de um contexto institucional. Aqui se torna relevante a convergência com a perspectiva institucionalista de análise, apresentada no próximo item, que pode complementar tal discussão. Acredita-se, no entanto, em consonância com grande parte das referências teóricas da NSE, que

"a forma assumida pelas instituições é fortemente condicionada pelo conteúdo e pela estrutura das relações sociais nas quais a ação econômica está imbricada, ou seja, pela configuração das redes sociais" (RAUD-MATTEDI, 2005, p. 68).

Não se trata, porém, de reduzir a estrutura das relações às interações objetivas empiricamente observáveis. A ordem simbólica acerca do significado dessas relações precisa ser evidenciada, pois aí residem relações "invisíveis", como disputas e conflitos que não são apreendidas de primeira mão, a não ser pela representação social e pelo discurso. O significado que os atores atribuem a outros atores com que se relacionam e à própria relação é tão importante quanto mapear a rede que os integra.

Grande parte da análise de redes sociais negligencia ou considera inadequadamente a dimensão crucial dos sentidos e motivações subjetivas que as constituem (EMIRBAYER e GOODWIN, 1994). Como argumentaram Friedland e Alford (1999), é preciso compreender não apenas a maneira como as relações sociais se estruturam e se estabilizam no tempo, mas também o significado que os atores atribuem à sua participação nelas e os processos históricos associados à sua transformação. Nesse sentido, para além de analisar a morfologia das redes, é necessário verificar quais os elementos colaboram para o engajamento ou desengajamento dos atores nessas redes, o que pode ajudar a compreender as posições e oposições entre eles, bem como questões que condicionam a intervenção nos processos de desenvolvimento.

Para se trabalhar com o enfoque relacional da sociologia econômica no estudo do desenvolvimento rural, concorda-se com Schmitt (2011, p. 97) quando ela afirma que alguns dos principais fundamentos residem em compreender que os atores estão vinculados a inúmeras redes, conduzidas por princípios econômicos e não econômicos que interferem em suas ações. Os padrões de interação construídos entre os atores, os tipos de vínculos e suas posições nas redes passam a ser questões centrais em análises. A configuração das redes é relevante ao se considerar que ela exerce influência significativa sobre os projetos e a organização dos atores, como, por exemplo, condicionando o fluxo e a qualidade das informações e criando laços de confiança.

Long (2007), em sua abordagem teórica sobre desenvolvimento rural, argumenta que as práticas dos atores envolvem o manejo e coordenação de redes sociais, que imprimem várias expectativas 
normativas e compromissos nas relações que a constituem. Para o autor, as redes são compostas de conjuntos de intercâmbios e relações diretas e indiretas, desiguais e parciais, que evoluem e se transformam com o tempo. A morfologia das redes se torna relevante na medida em que a forma como os grupos sociais estão dispostos na estrutura é crucial para entender o compromisso ou a contraposição dos atores em certos projetos de desenvolvimento.

Assim como o conceito de redes, entende-se aqui que o aporte teórico da NSE oferece outros conceitos que poderiam ser apreendidos para se construir as referências de análise dos processos de desenvolvimento territorial rural. Optou-se neste ensaio por discutir três principais conceitos, considerados fundantes de uma abordagem relacional:

1. Imersão social ('social embeddedness'), que contribui para compreender como as escolhas e estratégias dos atores estão imersas em redes de relações sociais e que esta imersão imprime características particulares em suas intervenções;

2. Redes sociais ('social networks'), que possibilita compreender como um território é constituído a partir das relações sociais que conectam diferentes atores e que as características da estrutura dessas relações têm importância considerável sobre as ações; e

3. Capital social ('social capital') que, como proposto aqui, traduz características da ação coletiva, distinguindo diferentes tipos de vínculos sociais, interessando mais em tentar compreender a natureza das relações sociais ou engajamento dos atores na rede.

\subsection{Imersão social}

O enunciado básico deste conceito é de que a ação econômica é socialmente situada e não pode ser explicada apenas por motivos individuais ou pela determinação cultural, em concepções super ou subsocializadas da ação humana: os atores estão imersos em redes de relações sociais que lhes importam nas suas escolhas cotidianas. Granovetter (2003) defende, considerando os postulados de Polanyi (2000) sobre o condicionamento social das ações econômicas em sociedades pré-industriais, que a maior parte do comportamento humano (inclusive as atividades econômicas) encontra-se imerso em redes sociais também nas sociedades modernas. Por esta via, ganha propriedade o argumento de que as instituições econômicas são socialmente construídas (GRANOVETTER, 1992a).

Granovetter (1973, 2003) descortina uma dimensão estrutural da sociedade ao enfatizar as redes como categoria analítica, propondo uma tipologia específica para se distinguir os vínculos interpessoais: os laços fracos, aqueles de menor intensidade e frequência (como nas relações com amigos de amigos), e os laços fortes, de grande intensidade e alta frequência (como nas relações entre familiares e amigos mais íntimos). De acordo com Steiner (2006), o conceito de imersão social propõe uma descrição original do alicerce social das relações mercantis, útil para se entender a configuração das relações sociais que garantem a articulação entre os agentes nos mercados.

As conexões sociais entre os indivíduos configuram sua interação em sociedade e podem, por exemplo, ser importantes pontes para acesso a empregos, bens e serviços que dificilmente conseguiriam se não estivessem inseridos em suas redes de relacionamento. A "força dos laços fracos", como argumenta Granovetter (1973), reside justamente em lançar "pontes" entre um conjunto de atores que de outra forma se encontrariam isolados em suas redes sociais mais íntimas (laços fortes) ou se relacionariam entre si por meio de desvios estruturais muito longos.

Granovetter destaca a função de controle social que a imersão assume em relação às trocas econômicas, chegando a ser substituto funcional de dispositivos institucionais de regulação e responsável pela produção de confiança. Para ele,

“[o] argumento da incrustação [imersão] enfatiza, por sua vez, o papel das relações 
pessoais concretas e das estruturas (ou 'redes') dessas relações na origem da confiança e no desencorajamento da má-fé. A preferência dominante em negociar com indivíduos de conhecida reputação parece confirmar que poucos confiarão realmente quer na moral generalizada, quer nos dispositivos institucionais, para afastá-los de problemas" (GRANOVETTER, 2003, p. 78).

O conceito de imersão social procura relativizar as motivações e preferências dos atores, ressaltando que os atores não se comportam nem tomam decisões como átomos fora de um contexto social e nem respondem passivamente a roteiros prescritos por categorias sociais que eles ocupam (GRANOVETTER, 2003). Ao contrário, suas tentativas de realizar ações com propósito estão imersas em sistemas concretos e contínuos de relações sociais. Faz-se necessário, assim, compreender a forma das redes e a natureza dos vínculos sociais em que o comportamento econômico está imerso para explicar com profundidade as estratégias e o desempenho das organizações.

Abramovay (2006) indica que a teoria do "embeddedeness" revela-se um recurso analítico adequado para compreensão de processos de desenvolvimento territorial, especialmente dois elementos centrais que influenciam para o sucesso das experiências de desenvolvimento: os mecanismos de cooperação entre atores e o papel dos mercados. Corroborando com esta perspectiva, Ortega (2008) afirma que um dos elementos de explicação do sucesso das experiências de desenvolvimento territorial é a medida de imersão social dos atores no território, que pode facilitar ou dificultar a cooperação e o acesso a outras redes mais amplas.

\subsection{Redes sociais}

Para Granovetter (1973), redes sociais são sistemas compostos por "nós" (indivíduos, grupos ou organizações) e conexões (relações) entre eles. A análise de redes sociais é considerada um tipo de abordagem sociológica que busca compreender os efeitos das relações sociais sobre o com- portamento individual e coletivo (MIZRUCHI, 2006), partindo do pressuposto de que o tecido social é estruturado por inúmeras redes de relacionamento, que apresentam diversas naturezas. Um dos importantes trabalhos que focam o papel de certas estruturas de rede é o de Burt (1992). Para ele, os atores que mantêm melhores desempenhos são aqueles que estão vinculados a redes mais densas (e por isso de maior proximidade) e, ao mesmo tempo, a outras redes mais distantes, de laços mais fracos, mas que possibilitam contatos e informações não redundantes. ${ }^{5}$

Concorda-se aqui com Mizruchi (2006) que centrar as análises de processos sociais no Estado ou nos agentes do mercado, pode acabar ofuscando aquilo que é a matéria principal da vida social: as redes de relações sociais, que incorporam e transcendem simultaneamente as organizações e instituições convencionais de um território. As redes são, neste sentido, "a estrutura do campo no interior do qual estão imersos os atores sociais e políticos relevantes em cada situação concreta" (MARQUES, 1999, p. 46). A morfologia desta estrutura salienta que a forma como as relações se estabilizaram em um determinado tempo e espaço, definindo certas posições nas redes e, por isso, acessos e restrições a certos recursos (como informações), influenciam as estratégias e projetos dos atores.

Favareto (2010b) constata que

“a criação de instituições mais favoráveis à dinamização dos territórios e à diminuição das desigualdades parece ser fortemente influenciável por determinadas características da morfologia social local" (p. 313).

Pode-se argumentar, como exemplo, que estruturas sociais marcadas por uma maior descentralização do poder e das decisões nos territórios, com relações mais estáveis entre os atores, podem ser ambientes mais propícios para

5. Exemplos de estudos empíricos sobre como os tipos de laços sociais, a posição e a arquitetura das redes sociais afetam a ação econômica das organizações em um determinado setor podem ser encontrados em Baldi e Vieira (2006) e Marques (1999). 
a cooperação e a inovação, ao dinamizar as interações e a distribuição dos recursos.

Em relação à perspectiva analítica da morfologia das redes sociais, alguns autores têm definido o foco nas posições dos atores e de suas consequências. Essa abordagem posicional pode ser encontrada, por exemplo, no conceito de laços fracos de Granovetter (1973), que considera que laços fracos, definidos pela (e resultados da) posição dos atores na estrutura, são pontes para novas redes e, assim, para novas informações e acesso a outros recursos. Para Burt (1992), certas posições nas redes têm efeitos sobre o alcance de melhores posições e retornos individuais nas organizações. Já Nan Lin (1999) propõe que o acesso e a utilização de recursos sociais são em parte determinantes das posições em estruturas hierárquicas e do uso dos laços fracos. Mas, para este autor, apesar da importância da posição na rede para o acesso a recurso, é preciso considerar o tipo de recurso que é valorizado pelos indivíduos, argumento base para sua definição de capital social. Nestas abordagens, a localização nas redes condiciona a ação dos atores. O efeito da estrutura de rede é colocado em termos de fornecimento de benefícios e restrições que os atores devem explorar e gerenciar.

Conforme asseguram Borgatti e Foster (2003), os estudos que examinam as consequências das redes e das posições nas redes sobre os comportamentos são tipicamente consistentes com uma agenda estruturalista. Em geral eles possuem uma concepção pouco desenvolvida da agência humana, desconsiderada em favor dos condicionantes estruturais da ação, mesmo que a estrutura social seja considerada como rede de relações sociais. ${ }^{6}$ Ao contrário disto, Marques (1999) argumenta que as redes moldam as ações e as estratégias, mas estas também as constroem e reconstroem continuamente, configurando um

6. Radcliffe-Brown (1989) é um dos autores que chega a considerar estrutura social como rede de relações sociais, situada num dado lapso de tempo. Porém, sua concepção funcionalista de estrutura social se aproxima mais a uma analogia de estruturas orgânicas, em que a mudança é apenas residual. processo dinâmico baseado numa relação dialética entre as estruturas sociais e as ações dos atores.

Para Emirbayer e Goodwin (1994), a agência humana deve ser introduzida nas análises de rede, reduzindo o determinismo estrutural por meio de uma interpretação histórica e cultural, buscando compreender adequadamente a formação, a reprodução e a transformação de redes sociais. Nesta perspectiva, não basta identificar a forma da rede, mas o processo pelo qual ela assim se constituiu e que condiciona a organização dos atores. O papel dos conflitos nessa mudança morfológica ascende como fundamental.

Portanto, deve-se considerar por que certos atores, com determinadas características/atributos, assumem certas posições nas redes e como, historicamente, as redes são constituídas e atualizadas, buscando elucidar o dinamismo e a recursividade da estrutura social. Para Paes de Paula (2006), uma abordagem interacionista das redes, da forma que se propõe aqui, deve analisar como os participantes mudam o significado dos relacionamentos e quais são as consequências destas mudanças para a unidade social da qual eles fazem parte.

No campo de estudos do desenvolvimento rural, Murdoch (2000) é uma das principais referências no que se refere à adoção de um novo paradigma do desenvolvimento rural baseado nas redes. Para ele, a noção de redes contribui para superar o pensamento binário sobre o desenvolvimento rural (endógeno x exógeno), ao dar ênfase nas relações e não somente nos atores e seus papéis. Compreendendo um conjunto de relações que pode abranger diversos atores, a proposição do uso das redes como uma forma de apreciação mais complexa dos processos de desenvolvimento rural busca superar abordagens centradas no Estado e/ou no mercado. Pressupõe-se, assim, que mudanças nas redes sociais de um território, seja com a alteração de posições ou na coesão interna por meio do conflito, conduzem a mudanças sensíveis na maneira como os atores se relacionam entre si e como elaboram, aprovam e implementam seus projetos de desenvolvimento ao longo do tempo. 
O autor abre caminho para que a própria sociologia do desenvolvimento e a sociologia rural (re) descubram nas relações sociais uma fonte analítica de interpretação dos processos sociais rurais, reivindicando uma abordagem relacional para o desenvolvimento frente às tradicionais fórmulas funcionalistas de análise. Deixa claro, porém, que a referência às redes não fornece respostas precisas aos problemas do desenvolvimento rural, mas cria oportunidades de se repensar as abordagens tradicionais e ajustar novos ângulos para a análise das dinâmicas sociais de desenvolvimento. Neste sentido, as redes poderiam ampliar as possibilidades para se compreender a natureza complexa e multifacetada do desenvolvimento rural e, assim, rejeitar respostas uniformizadas e padronizadas de políticas internacionais.

Preocupado com a capacidade heurística da noção de redes e sua aplicação nos estudos do desenvolvimento rural, Murdoch (2000) sugere que não seja possível definir um único modelo de desenvolvimento para diferentes territórios. Ao contrário, é preciso reconhecer que existem diferentes tipos de rede, envolvidos em diferentes processos sociais de desenvolvimento, interagindo de diversas maneiras e com contextos particulares, o que implica diferentes estratégias, projetos e estilos de desenvolvimento rural.

\subsection{Capital social}

Pode-se conceituar capital social aqui, segundo Steiner (2006), como uma rede de relações duradoura entre indivíduos, mais ou menos institucionalizada, que constitui um recurso real ou potencial que pode ser mobilizado por eles para atingir seus objetivos. A exemplo de Steiner, boa parte da literatura contemporânea sobre capital social se apropria da noção de redes sociais, principalmente associando as redes como portadoras de recursos sociais. As redes são exploradas como elemento importante na promoção tanto de coesão social quanto na construção de conexões entre grupos sociais, destacando, assim, os tipos de vínculos sociais.
Woolcock (1998) apresenta a proposta de desenvolver a noção de capital social com base na imersão social ('social embeddedness'). O autor considera que, primeiro, a imersão em si pode tomar várias formas distintas, a depender da natureza dos laços sociais, e moldar de forma distinta os tipos de oportunidades e constrangimentos dos atores. Em segundo lugar, que a imersão em uma determinada rede possui custos correspondentes, e que tal custo parece mudar significativamente ao longo da trajetória de desenvolvimento.

O alto grau de densidade e fechamento caracterizando as relações sociais relativamente de pequena escala e troca informal, nos mercados de pequenas comunidades, por exemplo, poderia impor restrições consideráveis sobre seus membros em tentativas de participarem de redes de troca maiores, mais extensas e sofisticadas, coordenadas por instituições formais e pelo Estado. De acordo com Granovetter (1992b), os grupos coesos possibilitam um fluxo contínuo de informações entre os atores, mas também geram com frequência estruturas normativas e elementos culturais que exercem efeito sobre o comportamento de seus membros, buscando a manutenção da coesão interna. Por estas características, esses grupos são chamados pelo autor de redes de alta densidade.

Para analisar se os custos ou benefícios da imersão prevalecem em qualquer situação, os estudiosos começaram a sugerir que a presença ou ausência de um conjunto complementar de laços sociais autônomos precisavam ser incorporadas na análise. Isto significava observar em que medida os membros de uma comunidade ou município têm acesso a relações com atores de outras localidades (não membros). Nesta abordagem, a coordenação dos processos de desenvolvimento territorial requer que os atores e os grupos dos quais façam parte sejam capazes de manter ambos os laços sociais, "imersão" e "autonomia". É importante considerar, então, que assim como há formas diferentes de imersão, há também formas distintas, mas correspondentes, de autonomia. 
Woolcock e Narayan (2000) assinalam que na literatura sobre desenvolvimento dois tipos de capital social são frequentemente identificados: "bonding social capital", referente aos laços de união e proximidade dentro de uma comunidade coesa e "bridging social capital", referente à formação de pontes entre grupos diferentes. O primeiro se aproxima da noção de laços fortes e o segundo, da noção de laços fracos, como descritos por Mark Granovetter, o que sugere uma grande influência deste autor sobre tal abordagem de capital social. As diferentes formas de combinação destes dois tipos de capital social geram resultados distintos para o desenvolvimento.

Woolcock (1998) sintetiza sua noção de capital social com vistas à promoção do desenvolvimento, considerando estes dois tipos e sua perspectiva de integração entre os níveis micro e macro. Ele sugere que, em nível micro, operam dois tipos de capital social - de ligação ('linkage') e de integração ('integration'). Quanto mais densa e integrada a rede de relações sociais e a confiança generalizada dentro de um determinado grupo, maior a sua dotação de capital social de integração. Mas quanto maior a presença deste capital social, mais os membros tendem a ser desencorajados a moverem-se geograficamente (e também seus projetos), e a se engajarem em redes extragrupais ou extramunicipais. Por outro lado, quanto mais capital social de ligação, mais os indivíduos têm liberdade e oportunidade de participarem de uma ampla gama de atividades; mas pode faltar-lhes a base de uma comunidade estável para fornecer orientação, apoio e identidade para avançarem neste sentido, ou seja, eles têm ligação, mas não integração. Em nível macro, o autor caracteriza o capital social como a existência de sinergia institucional, relacionada às relações entre Estado e sociedade civil, e a integridade organizacional, dizendo respeito à credibilidade das organizações em seus campos de atuação.

Pode-se dizer que a operacionalização desses tipos de capital social em termos de desenvolvimento rural reside na análise da natureza das relações estabelecidas pelos atores de um território, tanto entre si, quanto com atores externos, seja por meio de organizações formais ou informais. Moyano-Estrada (1999) indica exemplos a este respeito. Para ele, a sinergia institucional se refere à cooperação entre associações agrárias, associações não agrárias e instituições públicas. A integridade organizacional está associada à eficiência conferida aos serviços prestados pelas organizações de agricultores e a seu reconhecimento e legitimidade pela sociedade. A integração se refere à participação dos agricultores em associações comunitárias e a identificação dos agricultores com um projeto associativo comum. Já a ligação ressalta a participação dos agricultores e suas organizações em associações extracomunitárias e em grupos de desenvolvimento rural em escala regional.

Em decorrência da identificação de tipos diferentes de capital social, constata-se que eles são acionados em diferentes etapas do processo de desenvolvimento e que nem todo tipo de capital social contribui com o desenvolvimento. O que em certa fase é registrado como benefício, em outra pode ser convertido em custo para a continuidade do processo.

“O capital social é, portanto, um componente fundamental, mas enigmático da equação do desenvolvimento, precisamente porque ele pode melhorar, manter ou destruir o capital físico e humano" (WOOLCOCK, 1998, p. 185).

Neste sentido, a operacionalização da noção de capital social para este quadro analítico reside na definição da natureza das relações intergrupos, nas características dos vínculos sociais que unem ou afastam os atores que compõem o território, e como tais vínculos possibilitam ou constrangem relações intermunicipais e extraterritoriais.

Precisa-se sublinhar, desde já, que as redes ou o capital social não devem ser abordados como instituições ou substitutos a elas. É de fundamental importância para o desenvolvimento desse campo de estudo que ele se abra para as contribuições de abordagens institucionalistas, articulando as relações sociais que tecem as redes aos contextos institucionais que lhe servem de referência (NEE e INGRAM, 1998). 


\section{Marco de análise institucional das dinâmicas territoriais de desenvolvimento}

Para construir um marco de análise institucional, que embase análises empíricas e que complemente outras abordagens teóricas na explicação de dinâmicas territoriais de desenvolvimento, mobilizou-se alguns pressupostos teóricos do novo institucionalismo em análise organizacional, que tem profundas raízes sociológicas, chegando a ser chamado por alguns autores de vertente sociológica do neoinstitucionalismo (POWELL e DIMAGGIO, 1999). Nesta vertente, as instituições são definidas a partir de regras e normas, mas consideram-se também os modelos mentais e morais, símbolos e construções cognitivas que fornecem significados que condicionam a ação humana. Esta vertente também ressignifica a cultura e os sistemas culturais como sinônimos de instituições, trazendo para a discussão as redes de relações sociais, hábitos e símbolos que influenciam modelos de comportamento e promovem mudanças institucionais (HALL e TAYLOR, 1996).

Segundo Peters (2003), o institucionalismo na sociologia e teoria das organizações considera que as normas e valores possuem papel central às organizações para explicar a conduta individual e coletiva. Os atores são considerados a partir de sua incorporação a uma complexa série de relações com outros atores. Um dos principais pressupostos defendidos pela nova versão deste institucionalismo é que os indivíduos não são autômatos que respondem passivamente a sua socialização, mas escolhem entre diversas influências e analisam e interpretam os significados de seus comportamentos e dos comportamentos de outros atores com quem se relacionam.

Apesar das diferenças, todas as vertentes neoinstitucionalistas apresentam pontos em comum. Elas se concentram na construção de ordens sociais locais, que poderiam ser chamadas de "campos", "arenas" ou "jogos". Estabilidade é uma das palavras que com maior frequência se associa à noção de instituição, significando a construção de rotinas às ações e certa segurança ontológica aos atores. Como argumenta Douglas (1998), uma instituição tornar-se estável significa assumir alguma forma reconhecível e, por isso, compartilhada por um mesmo grupo social, legitimada e aceita pelos seus membros. Em geral, o argumento básico e fundante é que as instituições importam para a vida social, e sua relação com a ação exige compreender que elas tanto capacitam quanto coagem os atores sociais.

A teoria neoinstitucional possui certa proximidade com a teoria da estruturação de Giddens: elas fornecem perspectivas complementares sobre a constituição e manutenção de sistemas sociais. Ambas compartilham a premissa de que a ação é, em grande parte, organizada por instituições e reconhecem que as instituições são criadas, mantidas e alteradas por meio da ação e das relações sociais (BARLEY e TOLBERT, 1997). Outra premissa fundamental compartilhada é que as "instituições são intersubjetivamente transmitidas" (PETERS, 2003, p. 210), isto é, dependem da interação social para sua construção e reprodução.

Auxiliar a esta compreensão é a abordagem de Berger e Luckmann (2011), para os quais as instituições podem ser entendidas a partir de um caráter rotinizado das ações que lhe reproduzem. O processo pelo qual se criam padrões de ação e interação na sociedade é a institucionalização, que resulta em instituições. Na origem deste processo reside a habituação. Qualquer ação repetida com frequência molda-se num padrão que pode depois ser reproduzido com economia de esforço, tornando-se um hábito. A habituação traz consigo o importante ganho psicológico de se limitarem as opções, conservando alguma estabilidade à atividade humana.

As instituições são, neste sentido, as tipificações de atores e de ações tornadas hábito, disponíveis a todos os membros do grupo social. Elas reproduzem e regulam um padrão de comportamento, produzindo estabilidade. São, assim, estruturas sociais; socialmente construídas por meio das interações (BERGER e LUCKMANN, 2011). A estrutura social é o somatório das 
tipificações e dos recorrentes padrões de interação estabelecidos pelo seu intermédio. De acordo com os autores, as instituições possuem sempre uma história da qual elas são produto, sinalizando a importância de se localizar temporalmente os processos de habituação.

Para Scott (1987), uma característica comum dentre grande parte das definições de institucionalização é reconhecer que se trata de um processo social no qual os membros de um grupo passaram a reconhecer e aceitar uma definição comum de certa realidade, cuja validade não está atrelada a pontos de vista particulares e é tida como legítima, como o modo como as coisas são ou deveriam ser feitas. Corrobora com este argumento a afirmação de Meyer e Rowan (1999) de que práticas institucionalizadas são como elementos "taken-for-granted" das organizações e grupos sociais.

É preciso considerar, ainda, que as ordens institucionalizadas variam ao longo do tempo, principalmente por que a desinstitucionalização é também um processo recorrente, levando invariavelmente a mudanças significativas nos repertórios de ação e nos padrões criados. Segundo Scott (1995), a desinstitucionalização é geralmente o princípio de uma mudança institucional, pois se refere ao enfraquecimento ou desaparecimento de instituições, quando as rotinas se esvanecem e as regras ficam difusas, desestabilizando as relações sociais. Acontece quando as regras estabelecidas são desafiadas pelos membros do grupo e passam a não regular mais os comportamentos sociais. Isto geralmente possui um caráter processual, como transição, e dificilmente ruptura, pois não representa o abandono geral das práticas anteriormente institucionalizadas, mas sua transformação.

A consideração de alguns autores de que as redes e comunidades podem se tornar instituições (PETERS, 2003) pressupõe um processo de institucionalização que possibilita a regulamentação e a racionalização das práticas e das relações. Ribeiro (2008) chega a conceituar as instituições como a cristalização de redes sociais, considerando que a institucionalização das redes gera um conjunto de normas e significados compar- tilhados que produzem estabilidade, coerência e identidade entre seus membros.

Zucker (1987) compartilha do argumento de que a institucionalização aumenta a estabilidade nos sistemas sociais, mas reforça seu caráter cognoscitivo. As estruturas organizacionais podem ser influenciadas por pressões decorrentes de dentro da própria organização, das estratégias dos atores e de coalizões internas, e não apenas por pressões provenientes de fontes externas. A organização passa a ser vista também como instituição, que cria significados sobre a realidade e elementos culturais que condicionam a interação entre seus membros.

Neste sentido, técnicas, serviços e políticas institucionalizados podem funcionar como mitos e muitas organizações os adotam cerimonialmente, mais do que por demandas de suas reais atividades de trabalho (MEYER e ROWAN, 1999). Essa dimensão simbólica das estruturas formais reflete a busca por apoio e legitimidade no campo em que a organização se insere, entrando frequentemente em conflito com critérios de eficiência. ${ }^{7}$ Sua legitimidade se baseia na suposição de que eles são racionalmente efetivos, o que não resulta necessariamente em serem tecnicamente mais eficientes. Para se tornarem legítimas, as práticas e estruturas institucionalizadas precisam ser compartilhadas pelo grupo, conscientemente conhecidas por outras organizações ou disponíveis para que assim sejam. De acordo com os autores acima mencionados, as organizações que incorporam elementos socialmente legitimados em suas estruturas formais o fazem para maximizar sua capacidade de sobrevivência, para tornarem-se igualmente legítimas e alcançarem melhores posições em suas redes de relacionamento e acessar recursos estratégicos.

Apesar de não se aprofundarem nos mecanismos de transmissão dos mitos, Meyer e Rowan (1999) mencionam as redes de relações sociais

7. Para dar substância a essa ideia é preciso deixar claro, como fez Scott (1987), que nenhuma organização é apenas um sistema técnico; todas são sistemas sociais [assimétricos] e existem em um ambiente institucional que tenta delimitar a realidade social. 
como suas difusoras. As relações sociais que possibilitam a proximidade entre organizações são vistas como canais de transmissão e captação de informações, de representações simbólicas, enfim, de uma série de conteúdos que as particularizam, mas que as tornam fundamentais para a coesão e também expansão de um campo organizacional. Mizruchi (2006) chama a atenção para esse papel das relações sociais, afirmando que a análise de redes sociais pode contribuir para explicar como símbolos e mitos se disseminam e por que alguns e não outros são adotados, independentemente de serem ou não mais eficientes em termos objetivos.

Neste ponto traz-se à tona a discussão tão cara ao institucionalismo sobre mudança institucional, pois ela pressupõe a institucionalização e a desinstitucionalização e, assim, uma mudança simbólica. A história já provou que as instituições não se eternizam em uma forma específica, com os mesmos valores, e que elas também podem desaparecer e dar lugar a alternativas. Isso varia de acordo com a sociedade e com a capacidade dos grupos sociais de imprimem novas lógicas e sentidos a suas ações na vida cotidiana. Barley e Tolbert (1997) definem mudança das instituições, em geral, como processos contínuos e situados historicamente. Conforme argumentam, as relações sociais constituem instituições diacronicamente, enquanto as instituições influenciam a ação sincronicamente, mas a mudança institucional sempre é contínua.

Uma importante perspectiva teórica institucionalista sobre o papel da ação na mudança institucional é apresentada por Fligstein (2007), a partir do conceito de "habilidade social" ('social skill'), construindo um fundamento sociológico da ação em oposição ao individualismo metodológico. Esta perspectiva torna-se relevante para este trabalho, principalmente ao passo que busca relativizar a ênfase institucionalista que diria que as regras e os recursos existentes em um território (campo) são os elementos constitutivos da vida social, e acrescentar que a capacidade dos atores de utilizarem habilmente estes elementos precisa ser considerada.
"A habilidade de motivar os outros a tomar parte em uma ação coletiva é uma habilidade social que se prova crucial para a construção e reprodução de ordens sociais locais" (FLIGSTEIN, 2007, p. 62).

Este conceito possibilita analisar o papel dos atores na construção e transformação de instituições.

Tendo por referência o conceito de "habilidade social" de Fligstein (2007), Abramovay (2006) argumenta que a cooperação nos territórios deixa de ser produto virtuoso produzido por certas circunstâncias históricas favoráveis (como em Putnam (1996) e Fukuyama (1996)) ou por certas políticas bem construídas (como em Evans (2004)) e passa a ser resultado da tentativa dos diferentes grupos sociais de moldarem suas regras básicas. Esse argumento denota a capacidade de agência dos atores, que não se inclinam simplesmente a constrangimentos estruturais opressivos.

A ação e as interações entre os atores, portanto, não são determinações do ambiente institucional. Os atores possuem habilidades, distribuídas assimetricamente, para realizarem seus interesses e construírem coalizões políticas. ${ }^{8}$ É por meio da interação social, de conflitos e crises entre os atores sociais, que as instituições são criadas e transformadas. Ressalta-se, então, uma dimensão política da construção social das instituições.

Nesta perspectiva as instituições são conceituadas como

"[...] regras e significados compartilhados (implicando que as pessoas estão conscientes delas ou que elas podem ser conscientemente conhecidas) que definem as relações sociais, ajudam a definir quem ocupa qual posição nessas relações e orientam a interação, ao proporcionar aos atores quadros cognitivos ou conjuntos de

8. Fligstein (2007) não advoga a favor de um comportamento individual autointeressado. Ele considera que os atores, de fato, buscam seus interesses e se envolvem em interações para realizá-los, mas também que os atores são "socializados" (coletivizados), possuindo ações motivadas e orientadas aos grupos dos quais fazem parte. 
significados para interpretar o comportamento dos outros" (FLIGSTEIN, 2007, p. 64).

Abordagens institucionalistas contribuem, assim, para compreender como a mudança institucional está relacionada a uma mudança nas relações sociais, de modo que não seja possível entender a conduta individual ou organizacional desvinculadas de um contexto social. Para Friedland e Alford (1999),

"é por meio das relações sociais concretas que os indivíduos e as organizações procuram alcançar seus fins, mas também dão significado à vida e reproduzem esses sistemas simbólicos" (p. 294, tradução nossa).

De acordo com estes autores, a participação dos atores em redes sociais deve ser analisada também e, sobretudo, em termos de seu significado simbólico, pois dificilmente a manutenção de uma relação se dará apenas por interesses materiais. À medida que a relação acontece, ela é interpretada pelos atores, os quais também são interpretados e representados uns pelos outros. As tipificações decorrentes desse processo condicionam a natureza do vínculo e os recursos e regras que estarão em jogo. Neste sentido, as mudanças institucionais não prescindem das relações sociais, ao contrário, estão associadas à criação de novas relações e novas ordens simbólicas.

Segundo Peters (2003), a ideia da existência de redes de diversos tipos que conectam atores públicos e privados tem sido a interpretação predominante na análise das instituições que possibilitam a relação entre Estado e Sociedade. O Estado deixa de ser o ator central no processo de construção de políticas e é percebido como um dos atores de uma rede que, sozinho, dificilmente promoverá mudanças institucionais. A rede formada pelo conjunto das interações entre diversos atores é concebida como uma estrutura que se define relacional e cognitivamente.

Estes argumentos questionam certos modelos institucionalistas que postulam o imperativo determinista dentro do qual um campo institu- cional supraorganizacional integrado normativamente determina as formas organizacionais e homogeneíza as organizações que dele fazem parte, difundindo processos isomórficos de mudança, como em DiMaggio e Powell (2005). Esse imperativo desconsidera a adoção de formas organizacionais particulares por ações políticas adaptativas que visam construir novas lógicas institucionais. ${ }^{9}$ Desconsidera, ainda, a existência de múltiplas lógicas institucionais disponíveis aos indivíduos e organizações como bases para suas ações em favor de um padrão institucional único.

\begin{abstract}
“Sem atores, sem subjetividade, não é possível explicar a mudança. E sem múltiplas lógicas institucionais disponíveis para proporcionar significados alternativos, é pouco provável que os sujeitos encontrem uma base para a resistência" (FRIEDLAND e ALFORD, 1999, p. 320-321, tradução nossa).
\end{abstract}

Essa visão relacional das mudanças institucionais é reforçada por Kirschbaum (2010), ao afirmar que a indução de padrões de interação entre grupos em uma organização ou entre organizações pelo ambiente institucional "não é 'mecânica' (total adesão) ou 'apenas cerimonial' (sem adesão aos elementos instrumentais originais), mas passa por um processo de negociação em vários níveis" (p. 17). O processo de difusão e tradução de práticas ou regras em uma organização ou entre organizações de um mesmo campo é, assim, um processo concomitante de formação e transformação de laços sociais. Com base nesse autor, pode-se argumentar que existe um aspecto negocial e interacional que caracteriza, por exemplo, a implementação de uma política pública cujas instruções normativas visam estabelecer formas de organização e interação entre atores em um determinado território. Este aspecto revela que o resultado das políticas pode ser determinado pela maneira como os atores negociam seu acesso a elas e a intervenção do Estado num território.

9. Lógica institucional, para Friedland e Alford (1999), se refere a um conjunto de práticas materiais e representações simbólicas que constituem princípios de interação e organização compartilhados por um determinado grupo social. 


\section{Quadro analítico}

Propor tal fundamentação teórica se alinha à necessidade de formulação de uma abordagem relacional das políticas e práticas de desenvolvimento nos territórios rurais. Isso reflete um afastamento da acepção de desenvolvimento de epistemologias positivistas predominantes no mainstream e de suas fundamentações básicas em teorias econômicas clássicas e métodos nomotéticos. Principalmente porque o ponto de partida não é exclusivamente a ordem instituída, mas os processos sociais pelos quais ela é construída. Esta proposição está na rota de uma tendência das ciências sociais em que, de acordo com Emirbayer (1997), pesquisadores estão procurando por abordagens que revertam a suposição básica das análises estruturalistas estáticas e se direcionem para uma realidade social em termos dinâmicos e processuais.

A ênfase de uma abordagem relacional, como se propõe aqui, reside em como relações sociais específicas são construídas, reproduzidas e transformadas nos territórios a partir de sua criação pelo Estado, influenciando e sendo influenciadas pela política pública. O território emerge, assim, como alicerce sobre o qual se processa uma dinâmica de desenvolvimento; que, neste caso, se analisa como uma dinâmica social, considerando o próprio território como um conjunto de relações sociais superpostas.

Isso pressupõe ir além dos desenhos institucionais e prescrições das políticas operacionalizadas pelo Estado e compreender a natureza dos projetos de desenvolvimento em seus contextos particulares e as relações sociais que os circunscrevem. O foco de análise sugerido aqui é, portanto, o dos processos sociais que constroem e dão sentido ao território. Trata-se das relações que vinculam ou afastam os atores, identificando a natureza dos conflitos e da cooperação entre eles e suas representações sobre o território.

Destarte, uma dimensão analítica que precisa ser considerada se refere à ação, que resgate a agência humana nos quadros teóricos sobre desenvolvimento rural, considerando a natureza das relações sociais, as representações sociais e os atores que de fato intervém no território. Emirbayer (1997) afirma que agência humana é comumente identificada com a noção "self-actional" da vontade humana. Por contraste, o ponto de vista relacional proposto pelo autor vê agência como inseparável do desdobramento dinâmico das situações cotidianas e implica o engajamento pelo ator em diferentes ambientes estruturais, tanto reproduzindo, quanto transformando as estruturas. $\mathrm{O}$ autor ainda acrescenta que a agência sempre deve ser considerada em relação a alguma situação, pois não se trata de um interesse pessoal, mas de uma espécie de capacidade; é sempre um processo dialógico no qual os atores, imersos na dureé da experiência vivida, interagem com outros atores em contextos de ação coletiva situados espaço-temporalmente (EMIRBAYER, 1997).

Uma análise da ação necessita também de uma contextualização institucional, ressaltando uma dimensão estrutural dos processos sociais. Contudo, estrutura não deve ser concebida $a$ priori como algo rígido e estático. Ao contrário, é associada à estabilidade, já que possui uma característica recursiva, sendo também processual. Não se concebe analisar qualquer fenômeno numa abordagem relacional sem propor uma interação recíproca entre a estrutura e a ação, na qual ambas se atualizam, produzindo mudanças - novas instituições, estratégias e projetos de desenvolvimento, por exemplo.

O quadro analítico que se propõe aqui, como um desdobramento teórico, parte do construto "dinâmicas sociais em territórios rurais", residindo aí o fenômeno que se pretende explicar como determinante do desenvolvimento territorial rural. A dinâmica social compreende a forma de organizar ('organizing') o território, os sentidos a ele atribuídos e as interações entre os atores, que constantemente são atualizados. Assim, cada território possui sua dinâmica particular, que denota ritmos e estilos diferenciados de desenvolvimento e de gestão das políticas públicas. A operacionalização da análise da dinâmica social como se concebe aqui pode ser dividida em duas 
dimensões analíticas principais: dimensão estrutural e dimensão acional, que abrigam categorias analíticas das quais se parte para a apreensão de uma realidade empírica.

A dimensão estrutural diz respeito a uma dimensão meso e macroanalítica, à realidade de regulação do território. Corresponde à sua morfologia social, ou seja, à forma como as relações sociais estão estruturadas e conformam certos arranjos organizacionais. Considera-se relevante nesta dimensão a morfologia da rede e suas configurações. Os padrões institucionais, principalmente normativos e coercitivos, (impostos pelo Estado/política pública e regras tácitas e explícitas definidas entre os atores nos Colegiados, por exemplo) que influenciam o território também constituem um importante foco, já que são condicionantes das intervenções no território no âmbito da política territorial. O eixo de análise desta dimensão é, portanto, o contexto estrutural e institucional que envolve e condiciona as relações sociais no território. Por conseguinte, as principais categorias analíticas sugeridas a priori para orientar trabalhos empíricos foram:

1. Características morfológicas da rede que forma o território; e

2. Instituições, se referindo ao conjunto de regras e normas que orientam as interações entre os atores no território.

Entretanto, para não enfatizar uma análise estruturalista, é preciso considerar também uma dimensão acional, referindo-se a uma dimensão microanalítica, ao nível das ações e projetos coletivos. Significa identificar quem são os atores sociais que interagem no território e compreender a formação histórica das redes naquele contexto, porque os atores se organizam de determinada forma, os conflitos e disputas de poder inerentes ao território, as representações sociais sobre o território e sobre os outros atores membros. Ressalta-se também, assim, um elemento cognitivo, que envolve os sentidos atribuídos pelos atores à experiência territorial, à política e à rede que a operacionaliza e a maneira como isso influencia seu engajamento no território. O eixo de análise desta dimensão é, portanto, a historicidade e a natureza das relações que formam a rede do território e os sentidos a ela atribuídos. Por conseguinte, as principais categorias sugeridas a priori são:

1. Natureza das relações sociais; e

2. Sentidos do território e da rede que o constitui.

A seguir, a Figura 1 tenta sintetizar um esquema representativo dessa construção teórica, um "analytics framework", desde a proposição de referenciais teóricos à sua derivação em dimensões e categorias analíticas definidas para tentar explicar os construtos centrais.

Este quadro analítico não se encerra nesta síntese, pois o caráter relacional que se pretende exige argumentar sobre a integração analítica das dimensões e categorias, que, na Figura 1, é representada pelos fluxos recíprocos das setas ao nível das dimensões analíticas. As duas dimensões estão intimamente conectadas na análise da dinâmica social, pois são mutuamente influenciadas uma pela outra, ou seja, mantêm uma relação contínua e recursiva entre si. Esta integração analítica corresponde à uma análise sistêmica dos processos sociais nos territórios, de abstrair dos projetos territoriais e seus resultados práticos a sua essência, os processos que lhe são subjacentes, que lhe definem, mas que são de complexa apreensão se analisados de forma fragmentada e polarizada entre abordagens estruturais e voluntaristas. 
Figura 1. Representação do quadro analítico

\section{Desenvolvimento Territorial Rural}

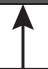

Dinâmicas Sociais em Territórios Rurais

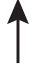

Construtos
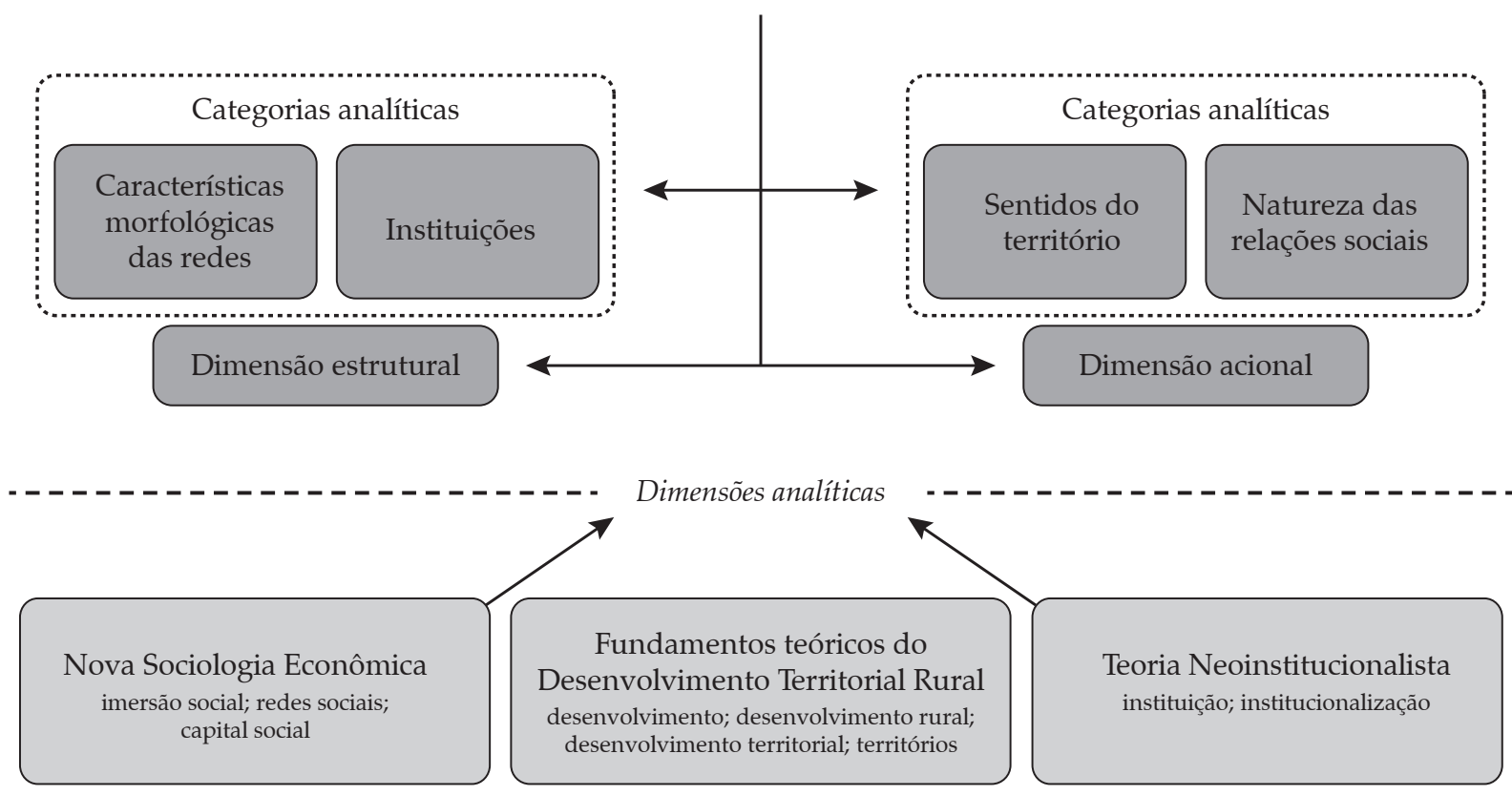

Suporte teórico

Fonte: Elaborado pelo autor.

Não obstante a separação esquemática das categorias analíticas, elas estão imbricadas nas experiências empíricas de desenvolvimento territorial, não existindo sobreposição de uma sobre outra na compreensão do objeto de estudo. Dispositivos institucionais buscam a reprodução de certos sentidos sobre o território, mantendo coesão e estabilidade entre os membros. Mas à medida que a natureza das relações entre eles é alterada, os sentidos atribuídos ao território também podem ser, repercutindo na estrutura das relações sociais e, assim, mudando certas instituições. Na medida em que surgem conflitos e disputas no território, por exemplo, para a apro- vação de um projeto a um determinado município, pode-se instigar a formação de coalizões políticas para conduzirem tal processo e viabilizarem interesses específicos, o que diretamente pode implicar mudanças no posicionamento dos atores na rede territorial. Portanto, depreende-se que as categorias analíticas se influenciam mutuamente, mantendo uma relação recíproca.

Nesse sentido, o leitor não precisa esperar encontrar, com a operacionalização dessa abordagem relacional do desenvolvimento territorial, a aplicação de uma teoria a um caso ou a uma realidade específica. Ela foi apropriada criticamente com a finalidade de criar um quadro analítico, 
uma lente para se enxergar um fenômeno em pauta. Isso traduz, assim, o ponto de vista a partir do qual pesquisas empíricas poderiam compreender o objeto de estudo, de modo em que as análises a serem realizadas não sejam produtos de uma especulação teórica, mas uma construção intelectual para interpretar problemas inseparavelmente empíricos e teóricos.

\section{Considerações finais}

Este ensaio buscou desenvolver um aporte teórico que avançasse rumo a uma abordagem relacional do desenvolvimento territorial rural, a partir de um quadro analítico que a sintetizava, visando mobilizar elementos teóricos para elucidar a dinâmica social de territórios rurais e seu papel no direcionamento de uma política pública. As categorias analíticas definidas podem possibilitar às pesquisas empíricas apreenderem como a política influencia a interação entre atores e como a configuração dessas interações influencia a operacionalização da política. Considera-se que a abordagem aqui empreendida poderá dotar as análises empíricas de sentidos diferentes daqueles que já se expressavam em trabalhos anteriores sobre o mesmo objeto, alcançando dimensões ainda pouco exploradas nos estudos do desenvolvimento territorial, como a rede de organizações, sua historicidade, suas configurações e os elementos sociais e institucionais que condicionam as intervenções dos atores no território, orientando sua trajetória de desenvolvimento. Essa construção teórico-analítica leva à premissa de que "atores", "redes" e "instituições" sintetizam os principais elementos constitutivos da dinâmica social dos territórios e, assim, elementos definidores da trajetória do desenvolvimento territorial rural.

Essa perspectiva vai de encontro à superação do caráter formalista e normativo da maioria das pesquisas. Além disso, como era objetivo, a proposta aqui apresentada é uma alternativa teórica a abordagens funcionalistas e estruturalistas que governam o mainstrean das teorias do desenvolvimento. Long (2007) é um dos autores que adverte sobre este caráter determinista da abordagem estruturalista na maioria dos estudos sobre desenvolvimento rural. Ele defende que o desenvolvimento não pode ser visto como o resultado de "forças externas", mas sim a partir das intervenções dos próprios atores, que operam cotidianamente um repertório variado de estratégias para a manutenção e melhoria de seus modos de vida. Argumento consonante ao que aqui se admite como parte da abordagem relacional.

Por outro lado, escapar de abordagens estruturalistas para residir sobre outras voluntaristas e individualistas, que se esforçam por explicar o desenvolvimento a partir da ação racional e interessada dos indivíduos, conduz ao entendimento de que as motivações e preferências dos indivíduos se tornam uma prisão individual, um guião do comportamento social, de modo que as instituições passam a ser tratadas como epifenômeno e as relações sociais apenas como acessórias na realização dos interesses pessoais. Polarizando as explicações do desenvolvimento rural em características macroestruturais ou na ação racional dos atores, as relações sociais acabam por ser marginalizadas analiticamente, e é exatamente na superação dessa perspectiva que a abordagem teórica proposta focaliza.

Esse empreendimento teórico sinaliza um novo paradigma do desenvolvimento rural, o qual se alinha às proposições de autores internacionais, como Long (2007), Murdoch (2000) e Woolcock (1998), assentado sobre uma perspectiva relacional, na qual as redes de relações sociais estão em seu âmago. Sobre esta referência, pode-se afirmar que a abordagem proposta possibilitará aos pesquisadores centrarem-se nas formas emergentes de interação que criam diferentes formas de organização nos territórios rurais, mais que no desenho dos modelos administrativos e das políticas públicas. Isso pressupõe compreender os arranjos organizacionais enquanto relações sociais estruturadas que conformam os territórios e influenciam e são influenciadas pela execução das políticas de desenvolvimento territorial.

Nesse sentido, a convergência entre a sociologia econômica e o institucionalismo, a partir das 
categorias propostas, elucida que a forma como se estruturam as relações sociais entre os diferentes atores de um território parece ser tão importante quanto as dotações naturais que este possui e o acesso dos atores às políticas públicas, pois condiciona a intervenção sobre o território, o seu uso e a própria implementação das políticas. Isso tem como consequência reconhecer que a posição dos atores nas redes que configuram um território tem importância central sobre suas condições de acesso a certos recursos. Tais posições são decorrentes de processos sócio-históricos, que levam à diferenciação entre os atores, pela posse de certos ativos econômicos, capacidades técnicas ou status, elementos que subjazem à implementação das políticas públicas.

\section{Referências}

ABRAMOVAY, R. O capital social dos territórios: repensando o desenvolvimento rural. Economia Aplicada, v. 4, n. 2, p. 379-397, 2000.

. Para uma teoria dos estudos territoriais. In: MANZANAL, M., NEIMAN, G. e LATTUADA, M. (Eds.). Desarrollo rural: organizaciones, instituciones y territorios. Ediciones Ciccus: Buenos Aires, 2006. p. 51-70.

BALDI, M. e VIEIRA, M. M. F. Calçado do vale: imersão social e redes interorganizacionais. RAE - Revista de Administração de Empresas, v. 46, n. 3, p. 16-27, 2006.

BARLEY, S. R. e TOLBERT, P. S. Institutionalization and structuration: studying the links between action and institution. Organization Studies, v. 18, n. 1, p. 93-117, 1997.

BERDEGUÉ, J. A., BEBBINGTON, A. e ESCOBAL, J. Conceptualizing Spatial Diversity in Latin American Rural Development: Structures, Institutions, and Coalitions. World Development, v. 73, p. 1-10, 2015.

BERGER, P. L. e LUCKMANN, T. A construção social da realidade. 33. ed. Petrópolis: Editora Vozes, 2011.

BOISER, S. Post-scriptum sobre desenvolvimento regional: modelos reais e modelos mentais. Planejamento e políticas públicas, n. 19, p. 307-343, jun. 1999.

BORGATTI, S. P. e FOSTER, P.C. The Network paradigm in organizational research: a review and typology. Journal of Management, v. 29 n. 6, p. 911-1013, 2003.
BOURDIEU, P. O poder simbólico. Rio de Janeiro: Bertrand Brasil, 1989.

BURT, R. S. Structural Holes: the social structure of competition. Cambridge: Harvard University Press, 1992.

DIMAGGIO, P. J. e POWELL, W. W. A gaiola de ferro revisitada: isomorfismo institucional e racionalidade coletiva nos campos organizacionais. RAE - Revista de Administração de Empresas, v. 45, n. 2, p. 74-89, 2005.

DOUGLAS, M. Como as instituições pensam. Trad.: Carlos Eugênio Marcondes de Moura. São Paulo: Editora da USP, 1998.

EMIRBAYER, M. Manifesto for a Relational Sociology. American Journal of Sociology, v. 103, n. 2, p. 281-317, 1997.

. e GOODWIN, J. Network analysis, culture, and the problem of agency. American Journal of Sociology, v. 99, n. 6, p. 1411-1454, 1994.

FAVARETO, A. Paradigmas do Desenvolvimento Rural em Questão. São Paulo: Iglu-Fapesp, 2007.

As políticas de desenvolvimento territorial rural no Brasil em perspectiva. Desenvolvimento em Debate, v. 1, n. 2, p. 47-63, 2010.

. e SCHRÖDER, M. Do território como "ator" ao território como "campo": uma análise da introdução da abordagem territorial na política de desenvolvimento rural no Brasil. In: 45을 CONGRESSO DA SOCIEDADE BRASILEIRA DE ECONOMIA E SOCIOLOGIA RURAL, 2007, Londrina. Anais... Londrina: Sober: 2007. p. 344-365.

.et al. Metamorfoses da dominação nos territórios rurais - qual a extensão das mudanças recentes nas regiões interioranas do Brasil contemporâneo? Estud. Soc. e Agric., v. 23, n. 2, p. 421-447, 2015.

FLIGSTEIN, N. Mercado enquanto política: uma abordagem político-cultural às instituições de mercado. In: MARQUES, R. e PEIXOTO, J. (Orgs.). A nova sociologia econômica. Oeiras, Portugal: Celta Editora, 2003, p. 195-227.

. Habilidade social e a teoria dos campos. RAERevista de Administração de Empresas, v. 47. n. 2, p. 61-80, 2007.

FRIEDLAND, R. e ALFORD, R. R. Introducendo de nuevo a la sociedad: símbolos, prácticas y contradiciones institucionales. In: POWELL, W. W. e DIMAGGIO, P. J. (Orgs.) El nuevo institucionalismo em el análisis organizacional. Trad.: Roberto Ramón Reyes 
Mazzoni. México: Fondo de Cultura Económica, 1999, p. 294-329.

FUKUYAMA, F. Confiança: as virtudes sociais e a criação da prosperidade. Trad. Alberto Lopes. Rio de Janeiro: Rocco, 1996.

GRANOVETTER, M. The strength of weak ties. American Journal of Sociology, v. 78, n. 6, p. 1360-1380, 1973.

Economic Institutions as Social Constructions: a Framework for Analysis. Acta Sociologica, v. 35, n. 1, p. 3-11, 1992a.

. Problems of explanation in economic sociology. In: NOHRIA, N. e ECCLES, R. G. (Eds.). Networks and Organizations: structure, Form, and Action. Boston: Harvard Business School Press, 1992b, p. 25-56.

Acção econômica e estrutura social: o problema da incrustação. In: MARQUES, R. e PEIXOTO, J. (Orgs.). A nova sociologia económica. Portugal: Celta Editora, 2003, p. 69-123.

HAESBAERT, R. O mito da desterritorialização: do "fim dos territórios" à multiterritorializadade. Rio de Janeiro: Editora Bertrand, 2006.

HALL, P. A. e TAYLOR, R. C. R. As três versões do neoinstitucionalismo. Lua Nova, n. 58, p. 193-223, 2003.

JEPPERSON, R. L. Instituiciones, efectos institucionales e Institucionalismo. In: POWELL, W. W. e DIMAGGIO, P. J. (Orgs.). El nuevo institucionalismo en el análisis organizacional. Trad. Roberto Ramón Reyes Mazzoni. México: Fondo de Cultura Económica, 1999, p. 193-236.

KIRSCHBAUM, C. Elementos para uma teoria institucional intra-organizacional. Perspec. Contemp, Edição Especial, p. 5-21, 2010.

LIN, N. Building a network theory of social capital. Connections, v. 1, n. 22, p. 28-51, 1999.

LONG, N. Sociología del desarrollo: uma perspectiva centrada en el actor. Trad. Horacia Farjado, Magdalena Villarreal e Pastora Rodríguez. México: Ciesas, 2007.

MARCH, J. G. e OLSEN, J. P. Neo institucionalismo: fatores organizacionais na vida política. Revista Sociologia Política, v. 16, n. 31, p. 121-142, 2008.

MARQUES, E. C. L. Redes e instituições na construção do estado e de sua permeabilidade. RBCS - Rev. Bras. de Ciências Sociais, v. 14, n. 41, p. 45-67, 1999.

As redes sociais importam para a pobreza urbana? DADOS, v. 52, n. 2, p. 471-505, 2009.

MEYER, J. W. e ROWAN, B. Organizaciones institucionalizadas: la estructura formal como mito y ceremonia. In: POWELL, W. W. e DIMAGGIO, P. J. (Orgs.). El nuevo institucionalismo en el análisis organizacional. Trad. Roberto Ramón Reyes Mazzoni. México: Fondo de Cultura Económica, 1999.

MIZRUCHI, M. S. Análise de redes sociais: avanços recentes e controvérsias atuais. RAE - Revista de Administração de Empresas, v. 46, n. 3, p. 72-86, 2006.

MOYANO-ESTRADA, E. El concepto de capital social y su utilidad para el análisis de las dinámicas del desarrollo. Economia Ensaios, v. 13, n. 2, v. 14, n. 1, p. 6-17, 1999.

MURDOCH, J. Networks: a new paradigm of rural development? Journal of Rural Studies, v. 16, p. 407-419, 2000.

NAVARRO, Z. O desenvolvimento rural no Brasil: os limites do passado e os caminhos do futuro. Estudos Avançados, v. 15, n. 43, p. 83-100, 2001.

NEE,V. e INGRAM, P. Embeddedness and beyond: institutions, Exchange and social structure. In: BRINTON,M.C.eNEE, V.(Eds.). The newinstitutionalism in Sociology. New York : Russel Sage Fundation, 1998.

ORTEGA, A. C. Territórios deprimidos: desafios para as políticas de desenvolvimento rural. Campinas: Editora Alínea, 2008.

PAES DE PAULA, A. P. Redes sociais e interorganizacionais: abordagem conceitual, agenda de pesquisa e estratégias metodológicas. In: III Congresso Latino-Americano de Ciência Política, Campinas. Democracia e Desigualdades. Campinas: UNICAMP/ ALACIP, 2006.

PECQUEUR, B. O desenvolvimento territorial: uma nova abordagem dos processos de desenvolvimento para as economias do Sul. Raízes: Revista de Ciências Sociais, v. 24, n. 1 e 2, p. 10-22, jan./dez. 2005.

PETERS, B. G. El nuevo institucionalismo: teoría institucional em ciência política. Trad. Verónica Tirotta. Barcelona: Editora Gedisa, 2003.

POLANYI, K. A grande transformação: as origens de nossa época. 2. ed. Rio de Janeiro: Elsevier, 2000.

PORTUGAL, S. Contributos para uma discussão do conceito de rede na teoria sociológica. Oficina do CES, nํ. 271, 2007.

POWELL, W. W. e DIMAGGIO, P. J. (Orgs.). El nuevo institucionalismo en el análisis organizacional. Trad. Roberto Ramón Reyes Mazzoni. México: Fondo de Cultura Económica, 1999. . e DIMAGGIO, P. J. Introducción. In: POWELL, W.W.e DIMAGGIO, P.J.(Orgs.). Elnuevo institucionalismo 
en el análisis organizacional. Trad. Roberto Ramón Reyes Mazzoni. México: Fondo de Cultura Económica, 1999. p. 33-75.

PRZEWORSKI, A. A última instância: as instituições são a causa primordial do desenvolvimento econômico? Novos Estudos, n. 72, 2005.

PUTNAM, R. Comunidade e democracia: a experiência da Itália Moderna. Rio de Janeiro: Ed. FGV, 1996.

RAFFESTIN, C. Por uma geografia do poder. São Paulo: Ática, 1993.

RAUD-MATTEDI, C. Análise crítica da sociologia econômica de Mark Granovetter: os limites de uma leitura do mercado em termos de redes e imbricação. Política E Sociedade, n. 6, p. 59-82, 2005.

RIBEIRO, G. L. Poder, redes e ideologia no campo do desenvolvimento. Novos Estudos, n. 80, março, 2008.

SCHMITT, C. J. Redes, atores e desenvolvimento rural: perspectivas na construção de uma abordagem relacional. Sociologias, v. 13, n. 27, p. 82-112, 2011.

SCHNEIDER, S. Território, Ruralidade e Desenvolvimento. In: VELÁSQUEZ LOZANO, F. e MEDINA, J. G. F. (Org.). Las Configuraciones de los Territorios Rurales en el Siglo XXI. Bogotá/Colombia:
Editorial Pontifícia Universidad Javeriana, 2009, v. 1, p. 67-108.

SCOTT, W. R. The adolescence of institutional theory. Administrative Science Quarterly, v. 32, n. 4, p. 493-511, 1987. . Institutions and Organizations. London: Sage Publication, 1995.

STEINER, P. A sociologia econômica. São Paulo: Editora Atlas, 2006.

SWEDBERG, R. Sociologia econômica: hoje e amanhã. Tempo Social, v. 16, n. 2, p. 7-34, 2004.

- e GRANOVETTER, M. Introduction. In: SWEDEBERG, R. e GRANOVETTER, M. (Eds.). The sociology of economic life. Oxford: Westview Press, 1992, p. 1-29.

WOOLCOCK, M. Social capital and economic development: toward a theoretical synthesis and policy framework. Theory and Society, v. 27, n. 2, p. 151208, 1998.

. e NARAYAN, D. Social capital: implications for development theory, research, and policy. The World Bank Research Observer, v. 15, n. 2, p. 225-49, 2000.

ZUCKER, L. G. Institutional theory of organization. Annual Review of Sociology, v. 13, p. 443-464, 1987. 
